\title{
Implikasi Pendidikan Agama Islam dan Responsi terhadap Keaktifan Salat Berjamaah Mahasiswa di Fakultas Ekonomi dan Bisnis, Universitas Medan Area
}

\author{
Fauji Wikanda \\ Fakultas Ilmu Sosial Politik, Universitas Medan Area, Indonesia \\ Diterima: Desember 2018; Disetujui: Desember 2018; Dipublish: Desember 2018 \\ E-mail: wikanda fauii@vahoo.com
}

\begin{abstract}
Abstrak
Tulisan ini bertujuan untuk mengetahui pelaksanaan mata kuliah pendidikan agama Islam dan responsi serta implikasinya terhadap keaktifan salat berjamaah mahasiswa di Fakultas Ekonomi Universitas Medan Area. Berdasarkan data dilapangan dan analisis, ditemukan: Pertama, pelaksanaan pendidikan agama Islam mencakup tujuan, kurikulum, proses belajar mengajar, evaluasi dan responsi mata kuliah pendidikan agama Islam. Kedua, keaktifan salat berjamaah mahasiswa di Masjid kampus merupakan hasil dari kegiatan responsi mata kuliah pendidikan agama Islam yang dilakukan oleh dosen mata kuliah pendidikan agama Islam.
\end{abstract}

Kata Kunci: Pendidikan Agama Islam, Responsi, Salat Berjamaah.

\begin{abstract}
This study aims to determine the implementation of Islamic religious education courses and responsiveness and their implications for the activity of the prayer of the students in the Faculty of Economics, University of Medan Area. This study uses a qualitative method. The process of collecting research data uses qualitative analysis techniques with steps to explain data and draw conclusions. Based on data in the field and analysis, this study found: First, the implementation of Islamic religious education includes goals, curriculum, teaching and learning process, evaluation and responsiveness of Islamic religious education courses. Second, the activeness of the prayers in the congregation of students at the campus mosque is the result of the activities of the Islamic religious education courses conducted by lecturers of Islamic religious education courses.
\end{abstract}

Keywords: Islamic Education, Responsiveness, Congregational Prayer

How to Cite: Wikanda. F. (2018). Implikasi Pendidikan Agama Islam dan Responsi terhadap Keaktifan Salat Berjamaah Mahasiswa di Fakultas Ekonomi dan Bisnis Universitas Medan Area. Journal of Education, Humaniora and Social Sciences (JEHSS). 1 (2): 117-121.

\section{PENDAHULUAN}

Pendidikan agama Islam sebagai bagian yang tidak terpisahkan dari sistem pendidikan nasional, eksistensinya sangat urgensif dalam rangka mewujudkan pendidikan nasional khususnya membentuk manusia yang beriman dan bertaqwa kepada Tuhan Yang Maha Esa. Di dalam UU No. 20 tahun 2003 tentang pendidikan nasional dijelaskan bahwa tujuan pendidikan nasional adalah untuk berkembangnya potensi peserta didik agar menjadi manusia yang beriman dan bertaqwa kepada Tuhan Yang Maha Esa berakhlak mulia, sehat, berilmu, cakap, kreatif, mandiri, dan menjadi warga negara yang demokratis serta bertanggungjawab (UU. No. 20 Tahun 2003 tentang Sistem Pendidikan Nasional, pasal 3.)

Pendidikan Islam juga merupakan sarana terpenting diperlukan dalam membangun sumber usaha manusia dan menanamkan nilai-nilai kemanusiaan. (Wan Daud: 2003). Sedangkan menurut Al-Rasyidin pendidikan Islam didefenisikan sebagai suatu proses penciptaan lingkungan yang kondusif bagi memungkinkan manusia sebagai peserta didik untuk mengembangkan diri-fisik-jasmani dan non fisik-ruhani dan potensi yang dimilikinya-al-jism, al’aql, al-nafs, dan al-qalb-agar berkemampuan merealisasikan syahadah primordialnya terhadap 觗 $\mathrm{http}: / /$ mahesainstitute.web.id/ojs2/index.php/jehss

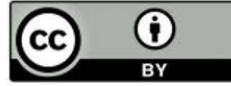


keberadaan dan kemahaesaan Allah Swt, melalui pemenuhan fungsi dan tugas penciptaannya, yakni sebagai 'abd Allah dan khalifah Allah. (Al Rasyidin: 2008).

Menggunakan sebagian besar waktu untuk hal-hal yang sia-sia bagi kebanyakan mahasiswa saat ini dianggap adalah hal yang wajar dan biasa. Apalagi di zaman sekarang, di mana arus globalisasi dan informasi yang serba terbuka membuat mahasiswa hanyut didalam suasana. Bahkan tidak jarang lupa terhadap kewajibannya sebagai mahasiswa yaitu belajar, dan lupa terhadap kewajibannya melaksanakan ibadah shalat. Firman Allah Swt. dalam Q.S. adzDzâriyât/51: 56:



Artinya: Dan Aku tidak menciptakan jin dan manusia melainkan supaya mereka mengabdi kepada-Ku. (Hikmah, 2009).

Melihat kenyataan yang ada, banyak mahasiswa yang kurang memahami tentang pendidikan agama Islam yang mengajarkan wajibnya ibadah shalat. Pada waktu shalat dhuhur dan ashar, seperti lembaga lainnya, Universitas Medan Area juga melaksanakan ibadah shalat berjama'ah bagi seluruh civitas akademik di lingkungan Universitas Medan Area. Namun kenyataannya banyak mahasiswa yang tidak ikut dalam shalat berjama'ah. Mereka asyik berbincang-bincang dengan teman dan makan di kantin. Bahkan tidak jarang aktivitas mahasiswa yang tidak ikut shalat berjamaah mengganggu ibadah shalat yang sedang dilaksanakan di Masjid kampus. Maka dari itu, pemahaman agama Islam mahasiswa harus ditingkatkan agar nilai-nilai keimanan dan ketaqwaan dapat tertanam di dalam hati dan diterapkan dalam kehidupan terutama dalam ibadah shalat.

Untuk mengantisipasi persoalan di atas, maka pendidikan agama Islam di Universitas Medan Area perlu direkonstruksi ulang agar dapat menghasilkan lulusan yang lebih berkualitas dan siap menghadapi "dunia" masa depan yang penuh dengan problema dan tantangan serta dapat menghasilkan lulusan yang memiliki sikap dan perilaku moral yang mulia. Pendidikan harus mampu mengemban misi pembentukan kultur akhlak mulia (character building) sehingga para mahasiswa lulusan dapat berpartisipasi dalam mengisi pembangunan di masa-masa mendatang tanpa meninggalkan nilai-nilai moral atau akhlak mulia.

Karena itulah, eksistensi kampus yang bernuansa akhlak mulia menjadi sangat penting tidak hanya untuk membekali para peserta didik dalam hal pengamalan nilai-nilai agama yang dianut, tetapi yang terpenting adalah mengantarkan mahasiswa agar menjadi manusia yang berbudi pekerti luhur (berakhlak mulia). Kampus ataupun perguruan tinggi membawa misi pokok untuk terwujudnya manusia (lulusan) yang memiliki akhlak mulia serta mampu mengamalkan ilmu dan keterampilan yang digelutinya dalam bentuk sikap dan perilaku tanpa meninggalkan nilai-nilai akhlak mulia tersebut.

Kampus sebagai lembaga pendidikan bukan hanya sebagai tempat untuk mentransfer ilmu pengetahuan semata, tetapi jauh lebih berat yaitu untuk mengarahkan, membentuk perilaku atau kepribadian mahasiswa. Berbagai upaya tentunya harus dilakukan secara optimal oleh setiap lembaga pendidikan guna mencapai tujuan tersebut. Bentuk usaha itu juga ditemukan oleh peneliti di Universitas Medan Area, dengan mengusung konsep visi kampus "menghasilkan sumber daya manusia (SDM) inovatif dan berakhlak" yang kemudian inilah kemudian yang menjadi tujuan lahirnya lembaga Pusat Islam di Universitas Medan Area (Buku Pedoman Mahasiswa Tahun Akademik 2014/2015.)

Universitas Medan Area melalui lembaga pusat Islam sangat aktif melaksanakan pembinaan ke-Islam bagi mahasiswa melalui kegiatan-kegiatan yang telah di program oleh lembaga tersebut. Beberapa kegiatan keagamaan yng dilakukan Pusat Islam dalam rangka pembinaan mahasiswa tersebut adalah belajar membaca al-Qur`an, shalat fardhu berjama`ah, ceramah ba'da jhuhur, bimbingan konseling Islam, bimbingan bagi muallaf, menyantuni anak yatim, koperasi Pusat Islam Universitas Medan Area, penerbitan buletin taqwa, penerbitan imsyakiyah ramadhan, pengajian tafsir Sya`rawi, pengajian arisan/bulanan, malam bina taqwa 
(MABIT), penyembelihan hewan qurban, peringatan hari besar Islam (PHBI), shalat Ied berjamaah (Buletin Taqwa, Universitas Medan Area Edisi ke 002 Jumadil Akhir/Tahun 1428 H/2007)

Kegiatan lain yang juga digiatkan adalah pelaksanaan kegiatan responsi pendidikan agama Islam yang berusaha menanamkan nilai-nilai berkaitan denga ilmu-ilmu agama dan akhlak yang mulia serta pengamalannya. Tujuan kegiatan ini adalah untuk mempermudah tercapainya visi Universitas Medan Area. Tulisan ini bertujuan untuk mengungkap bagaimana pelaksanaan mata kuliah pendidikan agama Islam dan responsi serta implikasinya terhadap keaktifan salat berjamaah mahaiswa di Fakultas Ekonomi Universitas Medan Area.

\section{PEMBAHASAN}

\section{Mata Kuliah Pendidikan Agama Islam}

Tujuan Mata Kuliah Pendidikan Agama Islam adalah sebagai kelanjutan dari pendidikan menengah, diselenggarakan untuk menyiapkan peserta didik menjadi anggota masyarakat yang memiliki kemampuan akademik dan professional yang dapat menerapkan, mengembangkan, dan menciptakan ilmu pengetahuan, teknologi dan seni. Sejalan denga hal tersebut maka, mata kuliah pendidikan agama Islam yang disampaikan kepada mahasiswa adalah sebagai upaya membentuk dan mengembangkan kepribadian individu secara utuh dan matang dalam aspek kognitif (pemahaman), afektif (perasaan), dan psikomotorik (pelaksanaan). Misi utamanya adalah membina kepribadian mahaiswa secara utuh dengan harapan bahwa mahasiswa kelak akan menjadi ilmuan/ akademisi atau professional yang memiliki keimanan yang kokoh dan bertaqwa kepada Allah SWT.

Senada dengan ungkapan di atas dosen mata kuliah pendidikan agama Islam memberikan penjelasan bahwa tujuan mata kuliah pendidikan agama Islam di Fakultas Ekonomi dan Bisnis Universitas Medan Area adalah mendidik dan menanamkan dinul Islam secara integral dalam aspek kognitif, afektif, konatif, dan psikomotorik. Sehingga mahaiswa memiliki kepribadian yang utuh dan mampu menumbuhsuburkan dan mengembangkan sikap positif dan cinta terhadap agamanya dalam berbagai kehidupan yang kelak diharapkan menjadi manusia yang bertaqwa kepada Allah SWT. (Wawancara: 2015).

\section{Kurikulum Mata Kuliah Pendidikan Agama Islam}

Kurikulum mata kuliah pendidikan agama Islam di Fakultas Ekonomi dan Bisnis Universitas Medan Area disebut dengan Kurikulum Pengembangan Kepribadian Mata Kuliah Pendidikan Agama Islam (MPK PAI). Inilah keunikan yang terdapat di UMA, kurikulum yang dilaksanakan disesuaikan dengan visi dan misi UMA. Kami juga berpedoman kepada GBPP dan SAP serta selalu berkoordinasi dengan pengurus Pusat Islam UMA. (Wawancara: 2015)

Mata kuliah pendidikan agama Islam di Fakultas Ekonomi dan Bisnis Universitas Medan Area bermuatan 3 SKS, diberikan dalam satu semester yang harus diambil mahasiswa di semester II. Proses pembelajaran berlangsung sebanyak 16 kali tatap muka. Yang kemudian dilanjutkan dengan kegiatan kelompok diluar ruang kelas.

Secara rinci tujuan dari kurikulum mata kuliah pendidikan agama Islam sebagai berikut: 1) memperluas wawasan pemahaman tentang ajaran Islam yang bersumber dari al-Quran dan hadis serta ijtima` ulama mengenai kehidupan masyarakat dan peradaban Islam (aspek kognitif); 2) Senantiasa memperdalam rasa iman di dalam hati sehingga mampu menghayati manisnya iman (halawatul iman) yang mendorong pencapaian derajat orang yang bertaqwa (aspek afektif); 3) Melahirkan motivasi yang kuat untuk melaksanakan ibadah mahdhah ibadah 'amah dengan penuh keteguhan dan didorong rasa ikhlas dan cinta kepada Allah (hablumminallah) yang ingin melahirkan damai dalam kehidupan bersama (aspek kognitif); 4) Mampu melaksanakan tuntunan ajaran Islam dengan menampilkan tingkah laku (akhlak) terpuji ditengah masyarakat dan dapat mengembangkan dan menampilkan kebaikan dalam bermuamalah yang membuahkan amal shaleh bagikehidupan dunia dan akhirat sehingga lahirlah manusia yang bersikap positif dan produktif yang berguna bagi bangsa. (Junus: 2014). 


\section{Proses Belajar Mengajar Mata Kuliah Pendidikan Agama Islam}

Pertama, kegiatan pembelajaran mata kuliah pendidikan agama Islam dimulai dengan berzikir dan berdo`a kepada Allah SWT secara bersama-sama. Dengan berzikir akan memberikan dampak luar biasa kepada hati semua mahasiswa sehingga mudah menerima pembelajaran dengan baik. Kedua, dosen menyampaikan materi perkuliahan dengan menggunakan slide show disertai dengan contoh-contoh yang relevan. Pembelajaran juga berpedoman kepada buku ajar mata kuliah pendidikan agama Islam serta buku responsi sebagai buku pegangan peraktek ibadah serta buku pengembangan kepribadian. Ketiga, kegiatan penutup yaitu memberikan penegasan atau kesimpulan dan penilaian terhadap penguasaan bahan kajian. Dalam pelaksanaan peraktek ibadah semua mahasiswa diwajibkan melaksanakan ibadah salat berjama`ah agar kemudian mahasiswa terbiasa beribadah. Materi peraktek ibadah meliputi ibadah salat dhuha, ibadah salat tasbih, ibadah salat jenazah, ibadah salat jumat serta membaca al-Qur`an.

\section{Evaluasi Mata Kuliah Pendidikan Agama Islam}

Pelaksanaan evaluasi mata kuliah pendidikan agama Islam Universitas Medan Area dilakukan dengan dua cara yakni penilaian awal dan penilaian akhir. Penilaian proses akan dilakukan oleh dosen mata kuliah pendidikan agama Islam sejalan dengan perkuliahan berlangsung. Sedangkan penilaian akhir dilakukan pada akhir perkuliahan dengan mengumpulkan nilai hasil ujian harian, ujian tengah semester (UTS) dan ujian akhir semester (UAS). Dalam hal ini evaluasi dibagi dua tahapan yaitu penilaian proses dan penilaian akhir. Pertama, penilaian proses digunakan dalam rangka membina, memperbaiki dan memperbaiki dan membentuk sikap mahasiswa. Kedua, penilaian hasil yang merupakan penilaian hasil belajar mahasiswa yang mencakup pengetahuan, keterampilan dan sikap. Pelaksanaan penilaian ini dilakukan melalui pengamatan, tes tertulis, tes lisan dan tes penugasan.

\section{Responsi}

Responsi adalah proses membina kepribadian mahasiswa secara utuh dengan harapan bahwa mahasiswa kelak akan menjadi ilmuan/akademisi atau profesional yang memiliki keimanan yang kokoh dan bertaqwa kepada Allah SWT. Penyampaian nilai -nilai karakter untuk membantu mahasiswa mengembangkan inti pokok dari nilai-nilai etika dan nilai-nilai kerja seperti integritas, kejujuran, tanggungjawab, kepedulian, keadilan, kerajinan, keuletan, dan ketabahan serta nilai-nilai lainnya (Yunus, 2014)

Paling tidak ada 14 karakter akhlak kebajikan pundamental yang ingin ditanamkan kepada mahasiswa di Fakultas Ekonomi Universitas Medan Area yakni: 1) Istiqamah; taat dan ikhlas beribadah, rajin beramal soleh serta konsisten meraih derajat ihsan; 2) Cinta kebenaran; jujur, terpercaya, komit serta gigih membela kebenaran; 3) Tanggungjawab; sikap dapat diandalkan, menghormati komitmen serta patriotisme. 4) Keadilan; bersikap wajar, menghormati pihak lain, santun/ beradap serta toleran; 5) Sikap positif; optimis, inisiatif, pengendalian diri serta terbuka; 6) Rasa kasih; empati, pemaaf, belas kasih serta patriotic; 7) Ketabahan; kesabaran, memiliki daya tahan, percaya diri serta ketekunan; 8) Kerja keras; prakarsa, kerajinan, disiplin, srta memiliki sasaran yang jelas; 9) Naluri sosial; bersih hati, ukhuwah, resolusi konflik, serta tolong menolong; 10) Penuh syukur; apresiatif terhadap karya orang lain, serta menerima kekurangan diri sendiri; 11) Kedermawanan; pemurah, mendahulukan orang lain, ukhuwah serta rela berkorban; 12) Himmah; mandiri, dinamis, dorongan berprestasi serta semangat berlomba; 13) Hikmat; penuh pengertian, kebijaksanaan, banyak akal serta mampu menyusun prioritas; 14) Pengendalian diri; mampu menunda kegembiraan, mampu menolak godaan, serta tidak berlebihan (Yunus, 2014)

Kegiatan responsi dilaksanakan di masjid kampus bertujuan agar mahasiswa terbiasa dekat dengan masjid. Penyampaian nilai karakter akhlak pun mengharuskan adanya praktek dalam bentuk ibadah agar mahasiswa mampu terjun kemasyarakat dengan bekal keilmuan dibidang agama. 
Diantara materi praktek ibadah mahasiswa adalah: 1) Praktek pengantar ibadah, seperti thaharah, (istinja', mandi, wudhu dan tayamum), salat fardhu, salat jumat, salat sunat (rawatib, tahajjud, dhuha, idul fithri, idul adha dan lainnya), fardhu kifayah jenazah, doa dan zikir sunnah; 2) Membaca al Quran berkaitan dengan makharijul huruf, hukum tajwid, serta yang lainnya; 3) Hafalan Juz 30 dari surah an Naba` hingga surah an Naas.

\section{Keaktifan Salat Berjamaah}

Kegiatan responsi di Fakultas Ekonomi Universitas Medan Area telah berjalan baik. Salah satu tujuan pelaksanaan itu adalah terciptanya insan yang memiliki kontrol terhadap dirinya serta tetap berkomitmen dengan ibadah-ibadah sehari-hari. Ini dapat dilihat dengan adanya peningkatan pada saat salat berjamaah yang dilakukan di masjid kampus. Bahkan pada saat pelaksanaan ibadah salat mahgrib jumlah mahasiswa sampai membeludak sehingga ibadah salat harus dilakukan sebanyak tiga kali berjamaah.

\section{SIMPULAN}

Mata Kuliah Pendidikan Agama Islam di Fakultas Ekonomi Universitas Medan Area mencakup tujuan, kurikulum, proses belajar mengajar serta evaluasi. Responsi Mata Kuliah Pendidikan Agama Islam di Fakultas Ekonomi Universitas Medan Area meliputi penanaman 14 karakter akhlak kebajikan pundamental serta praktek ibadah sehari-hari. Mata Kuliah Pendidikan Agama Islam dan Responsi di Fakultas Ekonomi Universitas Medan Area berpengaruh terhadap keaktifan salat berjamaah mahasiswa di masjid kampus.

\section{DAFTAR PUSTAKA}

Buletin Taqwa, Universitas Medan Area Edisi ke 002 Jumadil Akhir/Tahun 1428 H/2007.

Departemen Agama RI, (2009). Al-Qur`an dan Terjemahnya, Bandung: Diponegoro.

Team Penyusun, (2014). Responsi Mata Kuliyah Pendidikan Agama Islam, Pengembangan Karakter Akhlak Luhur Untuk Mahasiswa, Pendidikan 16 Karakter Kebajikan Fundamental, Medan: Medan Area University Press,

Team Penyusun, (2014). Pengembangan Kepribadian Dengan 16 Karakter Menuju Kebajikan Fundamental, Medan: Pusat Islam Universitas Medan Area,

Team Pengasuh Mata Kuliah Pendidikan Agama Islam, (2014). Mata Kuliyah Pengembangan Kepribadian, Pendidikan Agama Islam, Medan: Medan Area University Press.

Universitas Medan Area, Buku Pedoman Mahasiswa Tahun Akademik 2014/2015.

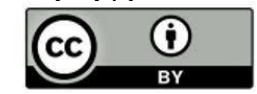

